\title{
The relationship between brand experience and consumer-based brand equity in grocerants
}

\author{
Hyeon Mo Jeon ${ }^{1} \cdot$ Se Ran Yoo ${ }^{2}$
}

Received: 23 July 2020 / Accepted: 9 November 2020 / Published online: 25 March 2021

(c) The Author(s), under exclusive licence to Springer-Verlag GmbH Germany, part of Springer Nature 2021

\begin{abstract}
This study proposes a model that applies brand experience and customer-based brand equity (CBBE) to verify leading variables that can increase brand loyalty in the fast-growing food service sector of "grocerants." For the empirical analysis, 384 foodservice consumers with experience of using seven South Korean grocerants were surveyed. The study identifies the influence of brand experience on perceived value and brand loyalty through brand awareness, brand association/image, and perceived quality. The study demonstrates that it is essential to build a CBBE that incorporates sensory, affective, intellectual, and behavioral factors to increase customer brand loyalty in the grocerants sector.
\end{abstract}

Keywords Grocerant · Brand experience · Consumer-based brand equity · Foodservice consumer

\section{Introduction}

People have less time to prepare food due to today's busy lifestyle. Many are looking for an easy, fast, and enjoyable way to meet their nutritional needs (Yoo et al. 2020). They want satisfying meals made from high-quality ingredients that require little preparation (Clenatano 2018). This has become especially apparent in the face of the widespread use of non-contact services caused by the COVID-19 pandemic worldwide (Jang and Lee 2020). This demand has effected changes in the food industry, which was previously dominated by grocery stores and restaurants.

Consumers are increasingly choosing products based on the experience offered in addition to the functional benefits of the products themselves (Zarantonello and

Se Ran Yoo

ser97@naver.com

1 Department of Hotel, Tourism, and Foodservice Management, Dongguk University-Gyeongju, Gyeongju, Republic of Korea

2 Department of Culinary and Service Management, Kyung Hee University, 7-13, Kyungheedae-ro 6-gil, Dongdaemun-gu, Seoul 02447, Republic of Korea 
Schmitt 2013). Related businesses have recognized the importance of consumer experience, and there are increasing meal options available on the market that are testament to this fact (Kim et al. 2019). Diners have started to look for food service options with unique features (Skrovan 2017). Thus, a new type of dining has emerged, called the "grocerant," where one can enjoy a healthy, fresh, high-quality, and convenient meal as well as appropriate services (Topper 2016). "Grocerant" is a compound word from "grocery" and "restaurant" (McGrace 2016).

Grocerants offer a complex experience in which the formerly clear distinctions between the grocery store and restaurant become ambiguous. Grocerant is a place that offers a new type of meal option (Varga 2018). Currently, grocerants show significant growth potential as more consumers choose to buy fresh ingredients and have their food cooked for them immediately at convenience stores, chain drug stores, grocery outlets, and other non-food retailers (Clenatano 2018). Grocerants are not only convenient for making food and meal purchases simultaneously, they also offer excellent value for money because only a small cooking fee is charged along with the price of the ingredients (Yoo et al. 2020). According to Forbes magazine, "The future of food shopping is not the restaurant or the grocery stores. Instead, it is the 'grocerant,' a hybrid of both, which may dominate" (Kim et al. 2019). According to Technomic Inc., a research and consulting firm, more American restaurant consumers choose local grocerants over traditional fast food or sitdown restaurants (Yoo et al. 2020). NPD Group, a research outfit in the US/Canada, reported that grocerants generated 2.4 billion new visits and over US\$ 10 billion in sales in 2016 (Charlebois 2017).

Fico Eataly World, which launched in Bologna, Italy in 2004, is famous for being the world's largest agri-food theme park. It offers its customers a food and farming experience that allows them to attend 30 events and 50 classes per day in an outdoor field (Kim et al. 2019). Wholefoods, a grocerant in the USA, transforms food shopping into a showtime arena, appealing to customers with sensational, emotional, and experiential experiences. Wholefoods offers fun experiences such as the Lamar Street Greens, where customers can buy organic agricultural products, salads, and wine, and Street Seafoods, where customers can enjoy 150 types of fresh seafood (Kim et al. 2019; Yoo et al. 2020).

One reason for the growth of grocerants lies in consumers' growing interest in experience, one of the major marketing trends of this time (Yoo et al. 2020). Consumers expect companies to give them an experience above and beyond the features and benefits of the products consumed (Pine and Gilmore 1999; Schmitt 2003). Companies today offer situations and factors that allow consumers to experience their brands, while consumers create their own unique experience of brands (Ha and Perks 2005). This has led companies to view consumers as emotional, active agents that have experienced the brand as a whole, and to study marketing communications and consumer experiences accordingly, rather than viewing consumers as strictly rational beings who are interested in the attributes and efficacy of the product alone (Zarantonello et al. 2007). This observation has brought about experiential marketing that emphasizes consumers' experience in the entire consumption process of brand products and services, as opposed to the traditional marketing that emphasized products' features and benefits (Schmitt 1999, 2003). A consumer's brand experience is created by their awareness, 
emotion, and behavior during interactions with marketing elements, such as goods, services, and brand space. Brand experience is not created automatically (Schmitt 1999). Rather, it is the consumer's subjective and internal behavioral response engendered by the brand (Brakus et al. 2009). Consuming a brand is not merely a matter of utilizing products and services, but a starting point for consumers to form brand loyalty, the highest concept in brand equity. It is the overall experience generated through various smaller experiences related to brand purchases (Morrison and Crane 2007).

As with other business sectors, the experience provided by grocerants affects brand equity, including brand awareness/association, perceived quality, and loyalty, as understood through the cognitive and behavioral choices consumers make when interacting with the brand (Moreira et al. 2017). Also, consumers who have had positive experiences with a brand have the potential to become loyal customers, which in turn builds a sense of familiarity and fondness, ultimately increasing brand value and exerting a strong influence on the company's brand equity (Aaker 1996; Brakus et al. 2009; CobbWalgren et al. 1995; Kirmani and Zelthaml 1993; Pine and Gilmore 1999; Schmitt 1999, 2003).

Customer-based brand equity (CBBE), which refers to the overall utility value that consumers assign to a particular brand, is a key factor in determining brand value from a long-term perspective (De Chernatony and McDonald 2003). Because brand equity is created through the organic relationships among various components that make up the brand, it is important to understand these relationships within the integrated constructs of $\mathrm{CBBE}$ in order to measure branding performance and efficiently manage the brand (Boo et al. 2009).

South Korean restaurants, as they experience the narrowing of the technological gap and high competition resulting from market maturity, may consider grocerants as a new dining business model. Distribution companies that handle groceries may also benefit from this possible new channel (Yoo et al. 2020). Currently, grocerants in South Korea are emerging as a restaurant-type brand rather than as a variant on the traditional grocery store. Thus, it is important to identify the brand experience, a major variable in grocerant consuming behavior, in order for the grocerant to grow into a competitive player in South Korea's restaurant sector, and for grocerants to build brand equity. By identifying the constructs of brand experience on the basis of Brakus et al. (2009), and identifying the relationships with the constructs of grocerants' CBBE, this study provides an integrated view that both benefits restaurant and food distribution managers for establishing a marketing strategy and a baseline model for the exploration of CBBE and brand experience in future research. The rest of this paper is structured as follows. Section 2 presents the literature review and proposes the hypotheses. Section 3 introduces the methodology. Section 4 presents the results. Section 5 presents the theoretical and practical implications. In the final section, conclusions are drawn and recommendations are proposed. 


\section{Literature review and hypotheses}

\subsection{Brand experience and brand equity}

Experience refers to one's observing or participating directly in a particular event, live or virtual (Schmitt 2003) wherein a consumer gains inspiration or knowledge from interactions with various elements of goods and services (Gupta and Vajic 2000). Experience may also include post-experience memories and the process of understanding (Alan et al. 2016), or any activity in which consumers see, hear, feel, think, or have relationships with others (Tynana and McKechnie 2009; Yoo et al. 2020). Thus, experience is a series of interactions between and among consumers, products, and services (Pentz and Gerber 2013).

Well-known studies on consumer experience include Pine and Gilmore's (1998) "experience economy" and the strategic experience module (SME) proposed by Schmitt (1999) (Chen and Lin 2018). Pine and Gilmore (1998) defined true experience as a single economic provision enveloping higher levels of products and services that consumers experience by directly participating in the production process. Schmitt (1999) further classified experience by identifying the consumer as an emotional being, arguing that emotions play a greater role in human decisions than reason. The study considered consumers as sense, emotion, think, act, and relate through experience. Comparing these two prior studies, Pine and Gilmore (1999) focused on the experience of spatial aspects ( $\mathrm{Su}$ et al. 2016), while Schmitt (1999) focused on the experiential elements offered by the brand. In current experiential marketing, the focus is on the brand experience itself which consumes products and services (Schmitt 2003). Marketers want to provide a unique and memorable experience to consumers who have both rational and affective characteristics (Moreira et al. 2017).

The structural equation modeling (SEM) proposed by Schmitt (1999) consists of conceptual elements in the basic information processing of consumers' brands, and was limited in that there was a lack of clarity in the classification of each component (Brakus et al. 2009) and in that it focused on consumers' behavioral responses to the brand's functional nature, neglecting to look at the overall experience arising from the brand itself (Zarantonello et al. 2007). Brand experience is a long-term and continuous process, not a short-term outcome, and should be understood as an ongoing process formed by consumers through stimulation by all factors related to the brand (Zarantonello et al. 2007). Considering this inherent complexity, Brakus et al. (2009) defined brand experience as a subjective and internal consumer response (sensations, feelings, cognition) as well as the behavioral response of consumers to brand-related stimuli. Their study divided brand experience into four types: sensory, affective, behavioral, and intellectual experience. These four brand experiences are consumers' processes of interacting with the brand, and the overall brand experience is complete if they are in harmony with each other.

When each of the brand experiences introduced earlier harmonizes with the others, the overall brand experience is complete and forms the basis of 
consumer-brand relationships (Brakus et al. 2009; Schmitt 1999, 2003). Consumer-brand relationships are the highest concept in Keller's (2002) understanding of CBBE. Zarantonello and Schmitt (2013) also argued that brand experience is more imperative than brand attitude to build strong brand equity. The relationship between brand experience and brand equity has been proven through various studies.

Brand equity is the consumer-perceived worth of a brand based on their valuation of the cohesive products or services offered by that brand (Yoo et al. 2000). It is the overall utility value that consumers give to the brand compared to competing brands (Vázquez et al. 2002). Among the components of brand equity, brand experience has been studied in relation to brand awareness, brand association/image, and perceived quality (Brakus et al. 2009; Ding and Tseng 2015; Keller and Swaminathan 2011; Moreira et al. 2017; Smith and Swinyard 1988; Yoo and Donthu 2001; Zarantonello and Schmitt 2013). Brand awareness results from the consumer's direct and repeated experience of the brand (Keller and Swaminathan 2011). Because a strong brand experience generates lasting memories (Dolbec and Chebat 2013; Keller 1993), brand experience can affect brand awareness. Brakus et al. (2009) also states that consumers who have had brand experience tend to recognize the brand easily or have strong associations, leading to brand loyalty. Yoo and Donthu (2001) confirmed that brand association/ image is enhanced by consumer-related experience or communication exposure, and that brand equity is further enhanced if this experience is consistent with the brand image. According to Ding and Tseng's (2015) research on various foodservice brands, brand experience is effective because it appeals to the cognitive dimension (brand awareness/association, brand quality) of brand equity and can inspire brand loyalty. From this perspective, consumers often think, evaluate, and remember the brand in terms of their experience with the brand. Since there can be high consistency between beliefs and attitudes following brand experience (Smith and Swinyard 1988), there may be changes in the brand's image depending on whether the brand has been experienced. And because consumers get information about the brand through experience in advance of making a purchase (Zarantonello and Schmitt 2013), they can form opinions about the brand's quality in advance. Perceived quality is consumers' subjective assessment of the overall value of the entity's products and services. High perceived quality means that consumers perceive the brand as superior (Zeithaml 1988). In a study by Ding and Tseng (2015), it was confirmed that foodservice consumers positively evaluate the perceived quality of a brand through brand experience.

Conversely, according to Iglesias et al. (2011) and Francisco-Maffezzolli et al. (2014), the relationship between brand experience and brand loyalty showed no significant direct effect. In addition, Moreira et al. (2017) confirmed that the purchase intention of catering consumers is not directly affected by the brand experience, but by the indirect effect of brand equity. Thus, the individual and holistic experiences argued by Brakus et al. (2009) and Schmitt (2003) encourage us to consider the sensory, affective, and cognitive aspects that have the potential to positively affect the brand equity. Based on these discussions, the following research hypotheses were established. 
Hypothesis 1 Brand experience has a significant positive effect on brand awareness.

Hypothesis 2 Brand experience has a significant positive effect on brand association/ image.

Hypothesis 3 Brand experience has a significant positive effect on perceived quality.

\subsection{Relationships among brand equity constructs}

Brand equity is made up of intangible assets that provide many benefits to an entity (Ding and Tseng 2015). Products or services that are branded stand out more than those that are not, under the same circumstances (Keller and Swaminathan 2011). Aaker (1991) argued that brand equity is the aggregate of assets and liabilities attached to a brand, and serves to increase or decrease the value that a product or service provides. Keller and Swaminathan (2011) defined brand equity as a differentiating effect resulting from brand knowledge in relation to consumer responses to marketing activities. Hence, the effectiveness of a brand should be assessed from the consumer's point of view (Blain et al. 2005). Building a strong consumer-based brand equity means increasing the share that brand occupies in consumers' minds and not necessarily in the market (Aaker 1996; Keller and Swaminathan 2011). Thanks to the intangible characteristics that make up brand equity, the concept can be understood in various ways (Simon and Sullivan 1993).

Most of the research on brand equity is based on the models presented by Aaker (1991) and Keller (1993) and adapted to suit the characteristics of the research. Aaker (1991) states that brand equity consists of brand awareness, brand association, perceived quality, and brand loyalty. Lassar et al. (1995) identified brand equity as a matter of social image, value, trust, and attachment. Cob-Walgren et al. (1995) considered brand association/image, brand awareness, and perceived quality as aspects of brand equity. Kirmani and Zeithaml (1993) proposed perceived quality, perceived value, brand attitude, and brand image as the basis of brand equity. Yoo et al. (2000) suggested brand loyalty, perceived quality, and brand awareness/association are the main factors in brand equity. Huang and Cai (2015) presented brand equity as brand knowledge (including brand awareness and brand image/association) and consumer response (brand resonance, behavioral intention). In the foodservice industry, Ding and Tseng (2015) presented brand equity as brand awareness/association and perceived quality, and Moreira et al. (2017) presented it as awareness/association, loyalty, and perceived quality. Thus, the researcher concludes that CBBE's constructs can be summed up as brand awareness, brand association/image, perceived quality, value, and brand loyalty.

\subsubsection{Brand awareness, brand association/image, perceived quality, and perceived value}

Perceived value is an integrated measure of the customer's perception of the costs and benefits arising from the use or experience of a product or service (Zeithaml 
1988). The value that the brand provides to consumers is an integral part of brand equity (Xixiang et al. 2016). Consumers rely on the perceived balance between product prices and their utility when choosing a brand (Lassar et al. 1995). Cost-benefit value is the most basic one that affects consumer behavior, yet it is a higher-level concept that includes interest, attitude, trust, opinion, and more. It is regarded as a good predictor of individual behavior (Gallarza and Saura 2006).

Looking at the relationship between the constructs of brand equity, many studies have found that brand awareness, brand association/image, and perceived quality directly affect perceived value (Chen et al. 2019; Pham et al. 2016; Ryu et al., 2008; Wang 2015). Wang (2015) explained that brand awareness is an important antecedent variable to perceived value through the research results that brand awareness of food service brand positively affects perceived food value. Chen et al. (2019) found that airline brand awareness, including brand popularity and association, has a positive effect on perceived value. Ryu et al. (2008) found that the image of a well-formed quick casual restaurant positively affected perceived value. Pham et al. (2016) found that the perceived quality of a quick-service restaurant is an important antecedent variable that increases perceived value. Based on these studies, the following hypotheses were established.

Hypothesis 4 Brand awareness has a significant positive effect on perceived value.

Hypothesis 5 Brand association/image has a significant positive effect on perceived value.

Hypothesis 6 Perceived quality has a significant positive influence on perceived value.

\subsubsection{Perceived value and brand loyalty}

Brand loyalty refers to a consumer's tendency to repurchase preferred products or services when they have developed deep, positive feelings for a particular brand (Hung et al. 2019). High brand loyalty features an increased tendency to recommend the brand to others and a decreased tendency to buy alternative brands (Mittal and Kamakura 2001). Dick and Basu (1994) defined brand loyalty as including not only repurchase behavior, but also emotional states such as attachment to companies, products, and services. The researchers also identified loyalty based on consumers' repeat purchase behavior (Elbeltagi and Agag 2016; Hung et al. 2019). Thus, loyalty is the most prominent consumer attitude/behavior studied (Alan et al. 2016).

The relationship between perceived value and brand loyalty has been verified in many studies (Aaker 1991; Jones et al. 2006; Overby and Lee 2006; Peña et al. 2017; Yoo et al. 2020). The higher the consumer's perception of value, the greater the likelihood they will repeat the same behavior. Since the consumer's perception of value is a motivating factor, it plays an important role in predicting loyalty, including future behavior (Overby and Lee 2006; Yoo et al. 2020). Aaker (1991) argued that the higher consumers perceive a brand's value, the higher their satisfaction with, 
and loyalty to the brand. Peña et al. (2017) identified a relationship between loyalty and consumers' perceived functional and emotional value in the context of a service entity. If a grocery store or restaurant enables consumers to obtain the product or service they want, consumers will appreciate the utilitarian value, and the probability of them revisiting and repurchasing it will increase (Jones et al. 2006). In addition, if a grocery store or restaurant allows consumers to experience pleasure during the purchase process, consumers will appreciate the hedonic value, which will lead to continuous visits and repurchases (Yoo et al. 2020). Based on these studies, the following hypothesis was established.

Hypothesis 7 Perceived value has a significant positive effect on brand loyalty.

All the hypotheses are represented in the theoretical model depicted in Fig. 1.

\section{Methodology}

\subsection{Sampling and data collection}

In this study, a sample was extracted from the population aged 20 and older living in South Korea who had used grocerants over the last six months. Major grocerants in South Korea include Gourmat 494, Lotte Mart Grocerant Market, Olive Market, PK Market, Shinsegae (SSG) Food Market, Dean and Deluca, and Eataly. Customers who purchased or ate food in these seven South Korean grocerants were sampled. The survey was conducted on 30 days between December 1, 2019 to January 10, 2020, including weekdays and weekends. Customers were surveyed at the exits of the grocerants. Researchers trained in the methods of this study conducted the surveys after checking with customers whether they had used the grocerants. All surveys were conducted with the self-reporting method

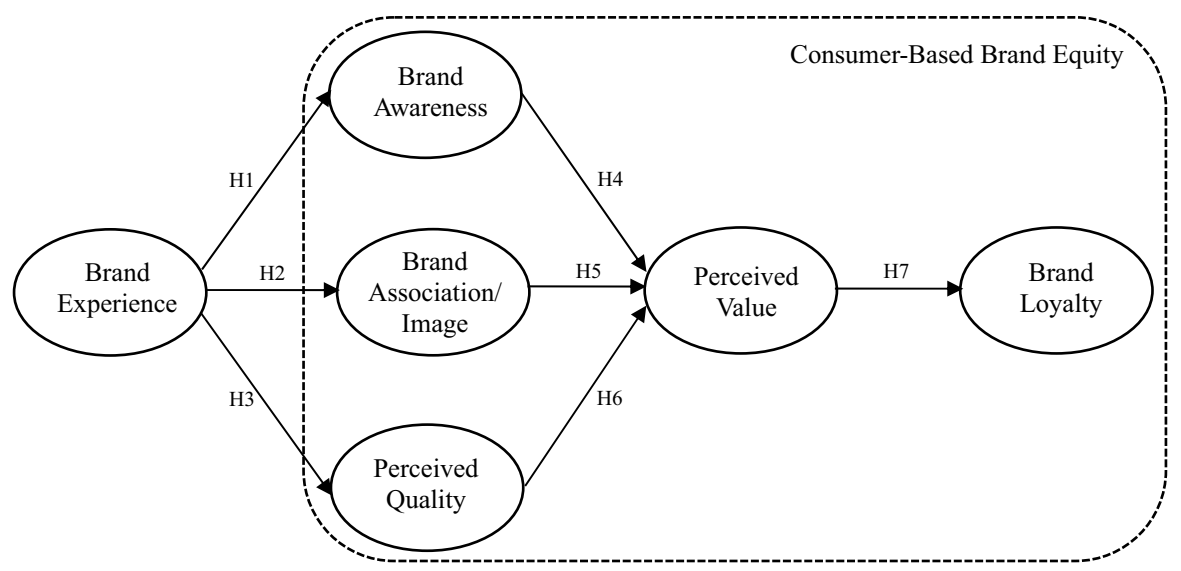

Fig. 1 Research model 
in which the respondents filled out the surveys directly after giving their consent to participate. A total of 410 surveys were recovered, of which 384 (93.7\%) were used as valid samples for analysis, excluding questionnaires deemed to be inconsistent or inappropriate. Before the final analysis, the data collected were carefully analyzed for normality, outliers, skewness, and kurtosis. In this study, the values of skewness and kurtosis for all variables were included, and the multivariate normality of data was examined and observed to be satisfactory through normality checks (West et al. 1995). The characteristics of the sample are shown in Table 1.

Table 1 Respondents' profiles

\begin{tabular}{lcc}
\hline Demographic characteristics & Frequency (n) & Percentage (\%) \\
\hline Gender & & \\
Male & 173 & 45.1 \\
Female & 211 & 54.9 \\
Age & & \\
20-29 years & 78 & 20.3 \\
30-39 years & 78 & 20.3 \\
40-49 years & 96 & 25.0 \\
50-59 years & 72 & 18.8 \\
Above 60 years & 60 & 15.6 \\
Educational level & & \\
High school & 43 & 11.5 \\
2-year university & 23 & 6.0 \\
4-year university & 232 & 60.4 \\
Graduate school & 85 & 22.1 \\
Monthly income & & \\
Below USD 2,000 & 50 & 13.0 \\
USD 2,000-2,999 & 77 & 20.1 \\
USD 3,000-3,999 & 73 & 19.0 \\
USD 4,000-4,999 & 66 & 17.2 \\
USD 5,000-5,999 & 44 & 11.5 \\
Above USD 6,000 & 74 & 19.3 \\
Occupation & & \\
Office workers & 169 & 44.0 \\
Professional job & 79 & 20.6 \\
Self-employed & 47 & 12.2 \\
Student & 26 & 6.0 \\
Sales and service & 23 & 10.4 \\
Others & 40 & \\
\hline & & \\
\end{tabular}




\section{Research instrument}

This study consists of nine factors: the sensory, affective, behavioral, and intellectual factors which comprise the constructs of brand experience, and brand awareness, brand association/image, perceived quality, perceived value, and brand loyalty which comprise the constructs of CBBE. The four factors in brand experience consisted of 12 items, three each, derived from Brakus et al. (2009), Cachero-Martínez and Vázquez-Casielles (2017), Choi et al. (2011). Among the factors contributing to brand equity, brand awareness was composed of four factors, cited from Atilgan et al. (2005), Ding and Tseng (2015), Yoo and Donthu (2001). Brand association was composed of three factors, derived from Huang and Cai (2015). Perceived quality was composed of four, cited from Ding and Tseng (2015) and Huang and Cai (2015). Brand value was composed of five factors taken from Kim et al. (2013), Lassar et al. (1995), Yoo et al. (2020). Brand loyalty was composed of five factors as well, cited from Anselmsson et al. (2017), Huang et al. (2015), Jeon et al. (2020).

This study first organized the survey questions through a literature review and modified them to suit the context of grocerants. After completing the first questionnaire, three professors of restaurant management and three operators of grocerants were consulted on the composition and content of the questionnaire. Since all the questions in the survey were developed in English in previous studies, the questionnaire was redeveloped using the double translation protocol (Harkness 2011). The questionnaire was developed in English first and then translated into Korean by two bilingual Korean professors who had sufficient understanding of this study in Korea. Prior to the survey, a pilot test was conducted to determine whether participants could fully comprehend the survey questions. After the pilot test, based on an exploratory factor analysis (EFA), questions that were difficult to measure accurately were removed and the remaining questions were modified as needed. After the survey was completed, the Korean version was translated back into English by two bilingual American professors from related fields in order to be of use in this study. There was little difference between the two English versions of the survey. All scale items were measured on five-point Likert-type scales ranging from strongly disagree to strongly agree.

\subsection{Analytical methods}

Our analysis used the Statistical Package for the Social Sciences (SPSS) 22.0 and Analysis of a Moment Structures (AMOS) 22.0. The demographic characteristics were analyzed using SPSS 22.0. Data analysis was carried out in Anderson and Gerbing's (1998) two-step approach-measurement model and structural model evaluation-in order to test our hypotheses. Confirmatory factor analysis (CFA) was first conducted to test the adequacy of the measurement model and assess composite reliability and convergent validity. In particular, CFA, being a high-order factor analysis, was conducted as a second-order factor. Structural equation modeling (SEM) was then performed to test hypothetical relationships among the six constructs proposed in the conceptual model. 


\section{Data analysis and results}

\subsection{Measurement model}

The goodness-of-fit of the measurement model was assessed using CFA, according to the cut-off values of seven fit indices: $\chi 2 / \mathrm{df}(<3)$, goodness-of-fit index $(\mathrm{GFI}>0.90)$, root mean square error of approximation (RMSEA $<0.08$ ), root mean square residual $(\mathrm{RMR}<0.08)$, normed fit index $(\mathrm{NFI}>0.9)$, incremental fit index $(>0.9)$, comparative fit index $(\mathrm{CFI}>0.9)$, parsimony normed fit index (PNFI $>0.5)$, and parsimony comparative fit index (PCFI $>0.5$ ) (Hair et al. 2016). Table 2 indicates the results of the CFA after removing one of the sensory items (i.e., "This grocerant is perceptually interesting") which reduced the goodness-of-fit of the model based on the squared multiple correlations (SMC >0.4) value.

The measurement model had a good fit with the data collected $\left(\chi^{2}=677.941\right.$, $\mathrm{df}=378, \mathrm{p}=0.000, \mathrm{CMIN} / \mathrm{df}=1.793, \mathrm{RMR}=0.021, \mathrm{GFI}=0.905, \mathrm{NFI}=0.897$, $\mathrm{IFI}=0.952$, CFI $=0.951$, PNFI $=0.730, \mathrm{PCFI}=0.773$, RMSEA $=0.046$ ). The adequacy of the measurement model was tested using standard criteria, namely reliability, convergent validity, and discriminant validity. First, reliability was assessed based on composite construct reliability (CCR) values. As shown in Table 2, all the values exceeded 0.7, demonstrating adequate composite reliability (Hair et al. 2016). The CFA results lend support to the convergent validity of the measurements, since standardized factor loading for all indicators is highly significant at $\mathrm{p}<0.01$ (Anderson and Gerbing 1988), ranging from 0.616 to 0.856 . Additionally, the average variance extracted (AVE) values of all constructs were higher than the minimum threshold of 0.5 , indicating the convergent validity of the measures (Hair et al. 2016).

To examine the discriminant validity of variables whose convergent validity had been established, we compared the square root of AVE of each latent variable against the corresponding correlation coefficients between potential variables. Table 3 shows that the square root of AVE of each latent variable is larger than its corresponding correlation coefficient, indicating adequate discriminant validity (Fornell and Larcker 1981).

\subsection{Common method bias}

Since all the variables in this study were collected from each respondent by selfreported response, the relationship between the variables may be distorted owing to common method bias (CMB) (Podsakoff et al. 2003). Therefore, to detect possible $\mathrm{CMB}$, the authors employed two statistical techniques. First, Harman's single-factor test was performed to minimize the distortion of the relationship between variables due to CMB. In Harman's single-factor test, We conducted a principal component analysis with the unrotated solution. According to Podsakoff and Organ (1986), when the single respondent variance is severe, a single factor is extracted from the principal component analysis or a single factor that explains most of the total variance is extracted. Traditionally, Harman's single-factor test indicates a problematic 
Table 2 Reliability and confirmatory factor analysis for measurement items

\begin{tabular}{|c|c|c|c|c|}
\hline Variables and Items & Loading & Cronbach's $\alpha$ & $\mathrm{CCR}^{\mathrm{a}}$ & $\mathrm{AVE}^{\mathrm{b}}$ \\
\hline \multicolumn{5}{|l|}{ Sensory } \\
\hline SE1 & .618 & .616 & .724 & .565 \\
\hline SE2 & .712 & & & \\
\hline \multicolumn{5}{|l|}{ Affective } \\
\hline AF1 & .647 & .783 & .823 & 609 \\
\hline $\mathrm{AF} 2$ & .734 & & & \\
\hline AF3 & .691 & & & \\
\hline \multicolumn{5}{|l|}{ Intellectual } \\
\hline IN1 & .752 & .775 & .781 & .545 \\
\hline IN2 & .740 & & & \\
\hline IN3 & .703 & & & \\
\hline \multicolumn{5}{|l|}{ Behavioral } \\
\hline BE1 & .721 & .782 & .833 & .625 \\
\hline BE2 & .785 & & & \\
\hline BE3 & .715 & & & \\
\hline \multicolumn{5}{|l|}{ Brand awareness } \\
\hline AW1 & .678 & .748 & .797 & .567 \\
\hline AW2 & .728 & & & \\
\hline AW3 & .674 & & & \\
\hline \multicolumn{5}{|c|}{ Brand association/image } \\
\hline IM1 & .658 & .704 & .811 & .588 \\
\hline IM2 & .709 & & & \\
\hline IM3 & .650 & & & \\
\hline \multicolumn{5}{|l|}{ Perceived quality } \\
\hline QU1 & .712 & .797 & .886 & .659 \\
\hline QU2 & .695 & & & \\
\hline QU3 & .722 & & & \\
\hline QU4 & .704 & & & \\
\hline \multicolumn{5}{|l|}{ Perceived value } \\
\hline VA1 & .670 & .822 & .885 & .606 \\
\hline VA2 & .669 & & & \\
\hline VA3 & .702 & & & \\
\hline VA4 & .676 & & & \\
\hline VA5 & .752 & & & \\
\hline \multicolumn{5}{|l|}{ Brand loyalty } \\
\hline LO1 & .732 & .856 & .910 & .669 \\
\hline $\mathrm{LO} 2$ & .758 & & & \\
\hline LO3 & .685 & & & \\
\hline LO4 & .708 & & & \\
\hline LO5 & .808 & & & \\
\hline
\end{tabular}

${ }^{\mathrm{a}}$ Composite construct reliability

${ }^{\mathrm{b}}$ Average variance extracted 
Table 3 Correlations of analysis between the variables

\begin{tabular}{llllllllll}
\hline Variable & 1 & 2 & 3 & 4 & 5 & 6 & 7 & 8 & 9 \\
\hline 1. SE & .752 & & & & & & & & \\
2. AF & .529 & .780 & & & & & & & \\
3. IN & .578 & .658 & .738 & & & & & & \\
4. BE & .479 & .642 & .610 & .791 & & & & & \\
5. AW & .309 & .482 & .440 & .466 & .753 & & & & \\
6. IM & .483 & .607 & .520 & .549 & .683 & .767 & & & \\
7. QU & .523 & .588 & .591 & .511 & .585 & .697 & .812 & & \\
8. VA & .588 & .671 & .638 & .647 & .595 & .698 & .709 & .778 & \\
9. LO & .510 & .625 & .613 & .570 & .576 & .726 & .732 & .732 & .818 \\
Mean & 3.835 & 3.780 & 3.691 & 3.480 & 3.658 & 3.701 & 3.823 & 3.811 & 3.748 \\
S.D & .669 & .621 & .654 & .710 & .683 & .604 & .567 & .598 & .615 \\
\hline
\end{tabular}

Diagonal elements show the square root of AVE. Below the diagonal is the corresponding correlation coefficient. All correlation coefficients were significant at the 0.01 level

common method variance (CMV) if an EFA with all study variables produces eigenvalues. This suggests that the first factor accounts for more than $50 \%$ of the variance among variables (Podsakoff and Organ, 1986; Fuller et al., 2016). After analyzing the measurement model, a principal component analysis was conducted by injecting the 31 remaining measurement items of brand experience and brand equity. The analysis results indicated that the variance explained by a single factor was $42.5 \%$, meeting the reference point of less than $50 \%$. These results imply that the possibility of CMB distorting the results of this study is low (Podsakoff et al. 2003).

Second, following Podsakoff et al. (2003), Williams et al. (2003), and Liang et al. (2007), we included a common method factor in the CFA model. Its indicators included all the principal constructs' indicators. Then, we calculated each indicator's variances substantively, as explained by the principal construct and method. The results demonstrate that the average substantively explained variance of the indicators is 0.501 , while the average method-based variance is 0.014 . The ratio of substantive to method variance is about $36: 1$. In addition, most method factor loadings are not significant. Given the small magnitude and insignificance of method variance, we argue that the method is unlikely to be a serious concern for this study.

\subsection{Structural model}

SEM was conducted using the AMOS 22.0 statistical package. To test the hypotheses established through the SEM path coefficients, the fit of the structural model describing the relationships among constructs was assessed. The model fit indices were $\chi^{2}=441.014, \mathrm{df}=226, \mathrm{p}=0.000, \quad \mathrm{CMIN} / \mathrm{df}=1.951, \quad \mathrm{RMR}=0.022$, $\mathrm{GFI}=0.915, \mathrm{NFI}=0.915, \mathrm{IFI}=0.957, \mathrm{CFI}=0.956, \mathrm{RMSEA}=0.050$, meeting the standard assessment criteria. The result of each hypothesis test describing the causal relationship between pairs of constructs is presented in Fig. 2. H1 was supported because brand experience positively and significantly influences brand awareness 


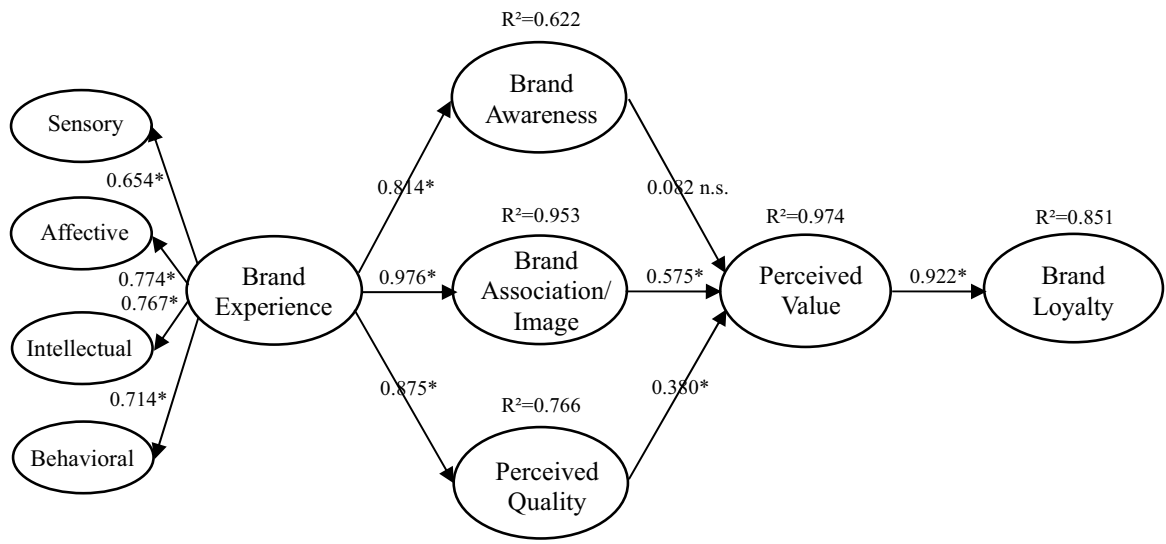

Fig. 2 Structural equation model with parameter estimates. $* \mathrm{p}<.01 ; \mathrm{n} . \mathrm{s} .=$ non-significant

$(\beta=0.814, \mathrm{t}=11.283, \mathrm{p}=0.000) . \mathrm{H} 2$ was supported because brand experience positively and significantly influences brand association $(\beta=0.976, \mathrm{t}=12.801$, $\mathrm{p}=0.000)$. H3 was supported because brand experience positively and significantly influences perceived quality $(\beta=0.875, \mathrm{t}=12.758, \mathrm{p}=0.000)$. H4 was rejected because brand awareness does not significantly influence brand value $(\beta=0.082$, $\mathrm{t}=1.183, \mathrm{p}=0.237)$. H5 was supported because brand association negatively and significantly influences brand value $(\beta=0.575, \mathrm{t}=4.906, \mathrm{p}=0.000)$. H6 was supported because perceived quality positively and significantly influences brand value $(\beta=0.380, t=4.255, p=0.000)$. Lastly, $\mathrm{H} 7$ was supported because brand value positively and significantly influences brand loyalty $(\beta=0.922, t=11.415, p=0.000)$.

\section{Discussion}

The results of the data analysis are as follows. First, brand experience significantly increased brand awareness, association/image, and quality. Owing to the sensory, affective, intellectual, and behavioral factors experienced in the grocerant, consumers tend to recognize the brand easily or have a strong association with it and evaluate quality more positively through their experience. This result is in great agreement with findings of previous studies related to experience (Brakus et al. 2009; Ding and Tseng 2015; Dolbec and Chebat 2013; Keller 1993; Yoo and Donthu 2001). This suggests that brand experience is also an important factor affecting the awareness, association/image, and perceived quality of brand equity in the restaurant sector.

Second, the relationship between the constituent factors of brand equity, brand association/image, and perceived quality were found to increase perceived value. The comfortable, clean, friendly impressions and food quality experienced in the grocerant increased the value to consumers. This result is in agreement with that of previous studies related to brand equity (Ryu et al. 2008; Pham et al. 2016). It also suggests that brand association/image and perceived quality are important factors 
influencing perceived value, whereas brand awareness is not. This result is in contrast to previous research results on brand equity (Chen et al. 2019; Wang 2015). Grocerant, which combines groceries and restaurants in South Korea, is still recognized as an unfamiliar restaurant to consumers. Therefore, it can be interpreted that consumers cannot perceive its value only by awareness of grocerant brand.

Third, it was confirmed that perceived value increased brand loyalty to the grocerant. If consumers experience the enjoyment of eating and the practical and economic value, it can be inferred that they are likely to revisit and recommend the brand to others. This result is consistent with that of previous studies (Jones et al. 2006; Yoo et al. 2020), which argued that perceived value is a positive predictor of brand loyalty.

\subsection{Theoretical implications}

From a theoretical point of view, this study sought to find CBBE for grocerants, which have recently been noted as the future of food shopping, and the prior variables of loyalty. Schmitt's (1999) SEM, which is known to enhance brand loyalty and create brand value, has limitations in that the classification of each factor is not clear and the theory does not look at the overall experience arising from the brand itself, as pointed out by Brakus et al. (2009). To overcome these limitations, brand experience theory proposed by Brakus et al. (2009) was applied. This design differentiates our study from others (Ding and Tseng 2015; Yoo et al. 2020) that have applied Schmitt's SEM in the restaurant industry.

In addition, this is the third empirical study of grocerants after Kim et al. (2019) and Yoo et al. (2020). Unlike the previous two studies, this study applied CBBE to comprehensively evaluate the cognitive and behavioral dimensions that would be part of the grocerant experience and to assess the overall brand experience. This study contributes to the literature on the grocerant experience by offering a novel study design. In particular, previous studies on the foodservice industry (Ding and Tseng 2015; Moreira et al. 2017) equated brand awareness and association/image and confirmed their relationship with brand experience. However, this study distinguishes between brand awareness and association/image. Thus, their relationship with brand experience was explored in more detail. It was confirmed that the foodservice consumer's brand experience has the greatest influence on brand association/ image.

It also sets itself apart from previous studies by applying perceived values overlooked in recent CBBE studies (Ding and Tseng 2015; Huang and Cai 2015; Keller and Swaminathan 2011) and identifying relationships between brand awareness, association/image, and perceived quality. In particular, the importance of brand association/image as the dominant influence on perceived value was confirmed. The findings indicate that grocerants' experiential marketing is effective because it can foster perceived value and brand loyalty by appealing to the cognitive dimension of CBBE (brand association/image and perceived quality). It also empirically confirms the claim by Brakus et al. (2009) that brand experience may increase grocerants' CBBE. Finally, this study applied the brand experience of Brakus et al. (2009) 
as a prior variable of CBBE for grocerants, a new type of dining-out business, and identified the structural relationship between the variables and the suitability of the model. This research design and the results contribute greatly to the dining-out brand experience theory.

\subsection{Practical implications}

From a practical point of view, business owners and other interested parties should take note of the importance of experience in increasing customers' loyalty to grocerants. Grocerants in the US were developed as a low-price concept and gradually became a higher priced option, whereas in South Korea grocerants were launched with higher prices and this trend continues (Kim et al. 2019). As South Korean restaurant customers pursue small luxuries, grocerants should appeal to the sensory and affective aspects of the customer's experience. The interior design of grocerants is a very important part of consumer experience and can reflect the luxury trend in South Korea. It is necessary to create a physical environment including sophisticated interior design and space layout, tableware, music, and lighting that can be as emotionally satisfying as a higher priced fine dining restaurant with all the convenience of the grocery story.

Entertainment programs may also contribute to providing customers with an exciting grocerant experience. In South Korea, grocerants are still in the early stages of development and typically lack programs for customers to participate in. The aforementioned features of a pleasing physical environment and high-quality food are no different from those offered by traditional restaurants. The unique quality of the grocerant is the customer experience. Customer participation programs related to food and food materials are essential. Italy's FICO Eataly World was conceptualized as an agricultural food theme park, while Whole Foods in the USA offers a variety of exciting experiential spaces where customers can easily participate in activities such as juice-making classes, social mixers, and more. Such experiences boost customers' perception of the overall quality of the venue. Thus, it is beneficial to appeal to customers through sensory and affective efforts as well as intriguing experiences.

In South Korea, the number of people living and eating alone is increasing. There are more options for dining alone in restaurants, and convenience stores and large discount stores offer a variety of simple menu items for one person. However, single-serving convenience food is not cheap when its quality is taken into consideration, and it can be a big financial burden for restaurant consumers. Focusing on this point, grocerants suggest developing take-out and delivery menus that allow customers to participate in the cooking process (such as meal kits) in addition to existing menu items. Meal kits typically include recipes and a set of prepared ingredients and seasonings, ready for cooking. This allows consumers to eat fresh and often healthier meals than if they were eating out. Because one does not have to buy and prepare the ingredients, meal kits are especially popular in single-person households or double-income households. In particular, during the COVID-19 crises, meal kits have a positive impact in that it allowed people to source food without leaving home. These take-out and delivery type meal kit products, in providing both 
pleasure and economic value, stimulate customers' curiosity and raise their evaluation of brand image and the overall quality of grocerants. This study also suggests cooking classes for customers who want to participate in the cooking process. Overall value and brand loyalty to grocerants will increase as customers who take such classes apply the educational experience in their lives and recognize that new and positive changes are taking place.

\section{Conclusion and limitations}

This study identified how grocerant brand equity is built through consumers' brand experience. It also discussed the relationship between the cognitive and behavioral variables within brand equity. For the verification, the model integrated a variety of explanatory variables such as brand experience, brand awareness, brand association/ image, perceived quality, perceived value, and brand loyalty. Data analysis results demonstrated that CBBE is a positive determinant of brand awareness, association/ image, and perceived quality. It was also confirmed that brand association/image and perceived quality are important factors in increasing brand loyalty through the value of grocerants. This empirical basis demonstrates the relationship between brand experience and CBBE. Thus, the theoretical framework proposed and tested in this study will serve as a basis for future experiential marketing research in restaurant studies.

There are some limitations to this study. First, since the survey was conducted in South Korea, the generalization of the results may be limited. It is not appropriate to apply the findings of this study to other countries as South Korea's grocerants are in an early stage. Second, we did not survey participants on the number of visits, preference, and amount spent, which could also affect the results of this study. If future studies consider such behaviors, a more comprehensive approach to grocerant marketing strategy could be found.

\section{Appendix A}

\section{Measurement items for study}

\begin{tabular}{ll}
\hline Measurement items & \\
\hline Sensory & \\
SE1 & This grocerant tries to engage my senses \\
SE2 & This grocerant has a sensory appeal \\
Affective & \\
AF1 & This grocerant tries to put me in a certain mood \\
AF2 & This grocerant makes me respond in an emotional manner \\
AF3 & This grocerant appeals to feelings \\
Intellectual & \\
\hline
\end{tabular}




\section{Measurement items}

\begin{tabular}{ll}
\hline IN1 & This grocerant tries to intrigue me \\
IN2 & This grocerant stimulates my curiosity \\
IN3 & This grocerant appeals to my creative thinking
\end{tabular}

Behavioral

BE1

BE2

BE3

Brand awareness

AW1

AW2

AW3

Brand association/image

IM1

IM2

IM3

Perceived quality

QU1

QU2

QU3

QU4

Perceived value

VA1

VA2

VA3

VA4

VA5

Brand loyalty

LO1

LO2

LO3

LO4

LO5
This grocerant makes me think about my lifestyle

This grocerant reminds me of activities that I can do

This grocerant leads me to think about my actions and behaviors

I am aware of this grocerant brand

Some characteristics of this grocerant brand come to my mind quickly

I can recognize this grocerant brand among competing brands

I feel comfortable about this grocerant

This grocerant is economical

This grocerant gives me the impression of being clean and friendly

This grocerant provides consistent service quality

This grocerant provides reliable food products

Compared to other grocerants, the quality of this grocerant is excellent

Overall, the quality of this grocerant is high

The use of this grocerant is fun and pleasant

The use of this grocerant is pragmatic and economical

Dining experience at this grocerant is worth the money

It is a good deal to dine at this grocerant compared to other restaurants

The overall value of dining at this grocerant is high

In the future, I will be loyal to this grocerant brand

This grocerant brand will be my first choice in the future

Compared to how I feel about other grocerant brands, this grocerant brand is important to me

I will recommend this grocerant brand to my friends or others

I will say positive things about this grocerant brand to others

Acknowledgements This research received no external funding.

Author contributions Se-Ran Yoo and Hyeon-Mo Jeon conceived and designed the experiments. HyeonMo Jeon performed the experiments and analyzed the data. Se-Ran Yoo and Hyeon-Mo Jeon wrote the paper. All authors contributed to reading and approved the final manuscript.

Funding No external funding was received for this work.

\section{Declaration}

Conflict of interest The authors declare no conflict of interest. 


\section{References}

Aaker DA (1991) Managing brand equity. The Free Press, New York

Aaker DA (1996) Building strong brands: what is a strong brand? The Free Press, New York

Alan AK, Kabadayi ET, Yilmaz C (2016) Cognitive and affective constituents of the consumption experience in retail service settings: effects on store loyalty. Serv Bus 10(4):715-735

Anderson JC, Gerbing DW (1988) Structural equation modeling in practice: a review and recommended two-step approach. Psychol Bull 103(3):411-423

Anselmsson J, Burt S, Tunca B (2017) An integrated retailer image and brand equity framework: re-examining, extending, and restructuring retailer brand equity. J Retail Consum Serv 38(September):194-203

Atilgan E, Aksoy Ş, Akinci S (2005) Determinants of the brand equity: a verification approach in the beverage industry in Turkey. Market Intell Plann 23(3):237-248

Blain C, Levy SE, Brent Ritchie JR (2005) Destination branding: insights and practices from destination management organizations. J Travel Res 43(4):328-338

Boo SY, Busser JA, Baloglu S (2009) A model of customer-based brand equity and its application to multiple destinations. Tour Manag 30(2):219-223

Brakus JJ, Schmitt BH, Zarantonello L (2009) Brand experience: What is it? How is it measured? Does it affect loyalty? J Mark 73(May):52-68

Cachero-Martínez S, Vázquez-Casielles R (2017) Living positive experiences in store: how it influences shopping experience value and satisfaction? J Bus Econ Manag 18(3):537-553

Chang TZ, Wildt AR (1994) Price, product information, and purchase intention: an empirical study. J Acad Mark 22(1):16-27

Charlebois S (2017). The grocerant-how smart grocery stores are becoming hybrids. Physorg. https:// phys.org/news/2017-11-groceranthow-smart-grocery-hybrids.html. Accessed 11 July 2020

Chen HT, Lin YT (2018) A study of the relationships among sensory experience, emotion, and buying behavior in coffeehouse chains. Serv Bus 12(3):551-573

Chen L, Li YQ, Liu CH (2019) How airline service quality determines the quantity of repurchase intention: mediate and moderate effects of brand quality and perceived value. J Air Transport Manag 75(March):185-197

Clenatano D (2018) Definition and examples of a grocerant. The balance small business. https://www. thebalance.com/consumers-dont-cook-from-scratch-they-go-to-grocerants-1326070. Accessed 11 July 2020

Choi YG, Ok C, Hyun SS (2011) Evaluating relationships among brand experience, brand personality, brand prestige, brand relationship quality, and brand loyalty: an empirical study of coffeehouse brands. https://scholarworks.umass.edu/gradconf_hospitality/2011/Presentation/22/. Accessed 11 July 2020

Cobb-Walgren CJ, Ruble CA, Donthu N (1995) Brand equity, brand preference, and purchase intent. J Advert 24(3):25-40

De Chernatony L, McDonald M (2003) Creating powerful brands, 3rd edn. Butterworth-Heinemann, Oxford

Dick AS, Basu K (1994) Customer loyalty: toward an integrated conceptual framework. J Acad Mark 22(2):99-113

Ding CG, Tseng TH (2015) On the relationships among brand experience, hedonic emotions, and brand equity. Eur J Mark 49(7/8):994-1015

Dolbec PY, Chebat JC (2013) The impact of a flagship vs. a brand store on brand attitude, brand attachment and brand equity. J Retail 89(4):460-466

Elbeltagi I, Agag G (2016) E-retailing ethics and its impact on customer satisfaction and repurchase intention: a cultural and commitment-trust theory perspective. Internet Res 26(1):288-310

Fornell C, Larcker DF (1981) Evaluating structural equation models with unobservable variables and measurement error. J Mark Res 18(1):39-50

Francisco-Maffezzolli EC, Semprebon E, Prado PHM (2014) Construing loyalty through brand experience: The mediating role of brand relationship quality. J Brand Manag 21(5):446-458

Fuller CM, Simmering MJ, Atinc G, Atinc Y, Babin BJ (2016) Common methods variance detection in business research. J Bus Res 69(8):3192-3198

Gallarza MG, Saura IG (2006) Value dimensions, perceived value, satisfaction and loyalty: an investigation of university students' travel behaviour. Tour Manag 27(3):437-452 
Gupta S, Vajic M (2000) The contextual and dialectical nature of experiences. In: Fitzsimmons JA, Fitzsimmons MJ (eds) New service development. Sage, Thousands Oaks, pp 33-51

Ha HY, Perks H (2005) Effects of consumer perceptions of brand experience on the web: brand familiarity, satisfaction, and brand trust. J Consum Behav 4(6):438-452

Hair JF, Hult GTM, Ringle C, Sarstedt M (2016) A primer on partial least squares structural equation modelling (PLS-SEM). Sage, Los Angeles

Harkness J (2011) Guidelines for best practice in cross-cultural surveys. University of Michigan Institute for Social Research, Ann Arbor

Huang ZJ, Cai LA (2015) Modeling consumer-based brand equity for multinational hotel brands-when hosts become guests. Tour Manag 46(February):431-443

Huang R, Lee SH, Kim HJ, Evans L (2015) The impact of brand experiences on brand resonance in multi-channel fashion retailing. J Res Interact Mark 9(2):129-147

Hung SW, Cheng MJ, Chiu PC (2019) Do antecedents of trust and satisfaction promote consumer loyalty in physical and virtual stores? A multi-channel view. Serv Bus 13(1):1-23

Iglesias O, Singh JJ, Batista-Foguet, (2011) The role of brand experience and affective commitment in determining brand loyalty. J Brand Manag 18(8):570-582

Jang HW, Lee SB (2020) Serving robots: management and applications for restaurant business. Sustainability 12(10):3998

Jeon HM, Jeon DH, Kim SH, Ki EH (2020) Consumers' perceptions of food service firms' philanthropy: roles of fit and perceived authenticity. Soc Behav Pers 48(3):1-11

Jones MA, Reynolds KE, Arnold MJ (2006) Hedonic and utilitarian shopping value: investigation differential effects on retail outcomes. J Bus Res 59(9):974-981

Keller KL (1993) Conceptualizing, measuring and managing customer-based brand equity. J Mark 57(January):1-22

Keller KL (2002) Strategic brand management: building, measuring, and managing brand equity, 2nd edn. Prentice Hall, Upper Saddle River

Keller KL, Swaminathan V (2011) Strategic brand management: building, measuring and managing brand equity, 5th edn. Pearson Education, India

Kirmani A, Zeithaml V (1993) Advertising, perceived quality, and brand image. In: Aaker DA, Biel AL (eds) Brand equity and advertising: advertising's role in building strong brands. Lawrence Erlbaum Associates, Hillsdale, pp 143-162

Kim S, Ham S, Moon H, Chua BL, Han H (2019) Experience, brand prestige, perceived value (functional, hedonic, social, and financial), and loyalty among grocerant customers. Int J Hosp Manag 77(January):169-177

Kim HJ, Park J, Kim MJ, Ryu K (2013) Does perceived restaurant food healthiness matter? Its influence on value, satisfaction and revisit intentions in restaurant operations in South Korea. Int J Hosp Manag 33(June):397-405

Lassar W, Mittal B, Sharma A (1995) Measuring customer-based brand equity. J Consum Mark 12(4):11-19

Liang H, Saraf N, Hu Q, Xue Y (2007) Assimilation of enterprise systems: The effect of institutional pressures and the mediating role of top management. MIS Q 31(1):59-87

McGrath M (2016) Why "grocerants" are the future of food shopping. Forbes. https://www.forbes.com/ sites/maggiemcgrath/2016/06/16/why-grocerants-are-the-future-of-food-shopping/\#511977ff1871. Accessed 11 July 2020

Mittal V, Kamakura W (2001) Satisfaction, repurchase intent, and repurchase behavior: investigating the moderating effect of customer characteristics. J Mark Res 38(February):131-142

Moreira AC, Fortes N, Santiago R (2017) Influence of sensory stimuli on brand experience, brand equity and purchase intention. J Bus Econ Manag 18(1):68-83

Morrison S, Crane F (2007) Building the service brand by creating and managing an emotional brand experience. J Brand Manag 14(5):410-421

Overby JW, Lee EJ (2006) The effects of utilitarian and hedonic online shopping value on consumer preference and intentions. J Bus Res 59(10-11):1160-1166

Pham LTM, Hong ND, Tuan MP (2016) The effect of brand equity and perceived value on customer revisit intention: a study in quick-service restaurants in Vietnam. Acta Oeconomica Pragensia 14-30

Peña AIP, Jamilena DMF, Molina MÁR (2017) The effects of perceived value on loyalty: the moderating effect of market orientation adoption. Serv Bus 11(1):93-116

Pentz C, Gerber C (2013) The influence of selected senses on consumer experience: a brandy case. Acta Commer 13(1):1-7 
Pine BJ, Gilmore JH (1998) The experience economy: work is theater and every business a stage. Harvard Business School Press, Boston

Podsakoff PM, Organ D (1986) Self-reports in organizational research: problems and prospects. J Manag 12(4):531-544

Podsakoff PM, MacKenzie SB, Lee JY, Podsakoff NP (2003) Common method biases in behavioral research: a critical review of the literature and recommended remedies. J Appl Psychol 88(5):879-903

Ryu K, Han H, Kim TH (2008) The relationships among overall quick-casual restaurant image, perceived value, customer satisfaction, and behavioral intentions. Int J Hosp Manag 27(3):459-469

Schmitt BH (1999) Experiential marketing. J Mark Manag 15(1-3):53-67

Schmitt BH (2003) Customer experience management. Wiley, New York

Simon CJ, Sullivan MW (1993) The measurement and determinants of brand equity: a financial approach. Mark Sci 12(1):28-52

Skrovan S (2017) Supermarket foodservice goes upscale: will shoppers bite? Food dive. https://www. fooddive.com/news/supermarket-foodservice-goes-upscale-will-shoppers-bite/437388/. Accessed 11 July 2020

Smith RE, Swinyard WR (1988) Cognitive response to advertising and trial: belief strength, belief confidence and product curiosity. J Advert 17(3):3-14

Su CJ, Lebrun AM, Bouchet P, Wang JR, Lorgnier N, Yang JH (2016) Tourists' participation and preference-related belief in co-creating value of experience: a nature-based perspective. Serv Bus 10(4):823-846

Topper A (2016) Foodservice trends 2017. Mintel. http://www.mintel.com/blog/foodservice-marketnews/the-rise-of-fast-fine-dining. Accessed 11 July 2020

Tynan C, McKechnie S (2009) Experience marketing: a review and reassessment. J Mark Manag 25(5-6):501-517

Vázquez R, Del Rio AB, Iglesias V (2002) Consumer-based brand equity: development and validation of a measurement instrument. J Mark Manag 18(1-2):27-48

Varga C (2019) The "grocerant" retail revolution. KTCHN rebel. https://www.ktchnrebel.com/grocerantsretail-restaurants/. Accessed 11 July 2020

West SG, Finch JF, Curran PJ (1995) Structural equation models with non-normal variables: problems and remedies. In: Hoyle RH (ed) Structural equation modelling: concepts, issues, and applications. Sage, Thousand Oaks, pp 56-75

Xixiang S, Gilal RG, Gilal FG (2016) Brand experience as a contemporary source of brand equity in 21st century: evidence from the Chinese consumer market. Int J Educ Res 4(9):63-76

Yoo B, Donthu N (2001) Developing and validating a multidimensional consumer-based brand equity scale. J Bus Res 52(1):1-14

Yoo B, Donthu N, Lee S (2000) An examination of selected marketing mix elements and brand equity. J Acad Mark Sci 28(2):195-211

Yoo SR, Lee SW, Jeon HM (2020) The role of customer experience, food healthiness, and value for revisit intention in grocerant. Sustainability 12(6):2359

Wang EST (2015) Effect of food service-brand equity on consumer-perceived food value, physical risk, and brand preference. British Food J 117(2):553-564

Williams LJ, Edwards JR, Vandenberg RJ (2003) Recent advances in causal modeling methods for organizational and management research. J Manag 29(6):903-936

Zarantonello L, Schmitt BH (2013) The impact of event marketing on brand equity. The mediating roles of brand experiences and brand attitude. Int J Advertising 32(2):255-280

Zarantonello L, Schmitt BH, Brakus JJ (2007) Development of the brand experience scale. In: Fitzsimons G, Morwitz V (eds) Advances in consumer research, vol 34. Association for Consumer Research, Duluth, pp 580-582

Zeithaml VA (1988) Consumer perceptions of price, quality, and value: a means end model and synthesis of evidence. J Mark 52(3):2-22

Publisher's Note Springer Nature remains neutral with regard to jurisdictional claims in published maps and institutional affiliations. 